
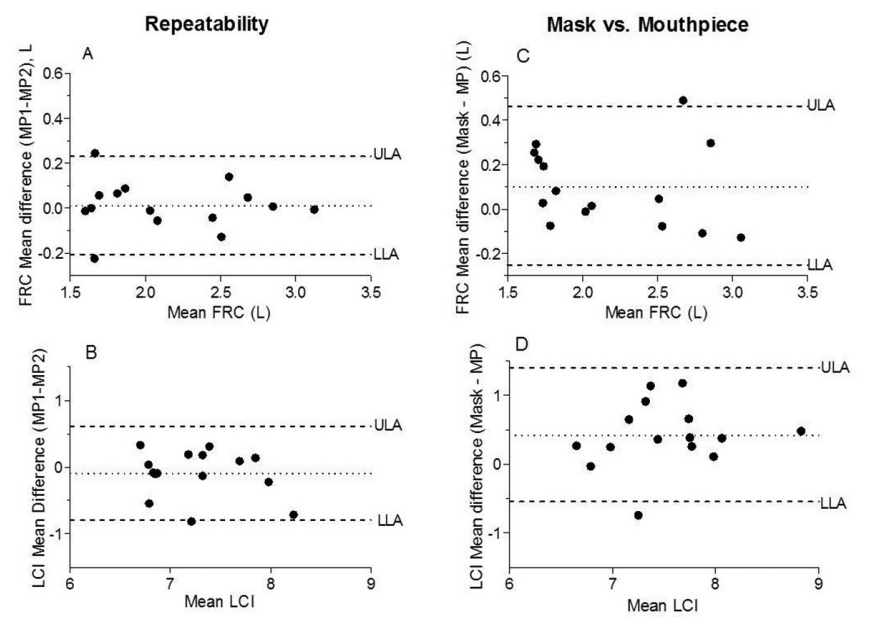

Abstract P101 Figure 1 A-D: Bland and Altman graphs for FRC and $\mathrm{LCl}$ showing within-test repeatability using the mouthpiece (Figure 1A and B) and comparison between Mask vs. Mouthpiece (Figure 1C and D). Dotted line denotes the mean difference and the dashed lines either side denote the upper and lower limits of agreement (ULA, LLA)

influence interpretation of results especially if different patient interfaces are used when collecting data in younger children.

\section{P102 RECOVERY OF BASELINE LUNG FUNCTION AFTER A PULMONARY EXACERBATION IN CHILDREN WITH PRIMARY CILIARY DYSKINESIA (PCD)}

M Sunther, S Carr, C Hogg, A Bush. Royal Brompton Hospital, London, UK

\subsection{6/thoraxjn-2014-206260.243}

Rationale Spirometry in children with cystic fibrosis (CF) frequently fails to return to baseline after treatment for a pulmonary exacerbation [Am J Respir Crit Care Med 2010; 182: 627-32]. It is unclear however how often lung function returns to previous baseline levels after treatment of a pulmonary exacerbation with intravenous antibiotics in children with PCD.

Objectives To determine in children with PCD: (1) the proportion treated for a pulmonary exacerbation who recover to baseline $\mathrm{FEV}_{1}$ within 3 months and at 12 months and (2) to try to identify factors which are associated with failure to recover spirometry.

Methods Cohort study using the PCD database for children at the Royal Brompton Hospital from 2003 to 2013. We selected

\section{Abstract P102 Table 1 Characteristics of patient cohort}

\begin{tabular}{|c|c|c|}
\hline Characteristic & $\begin{array}{l}\text { Responder }(\mathbf{n}=\mathbf{2 3}) \\
N(\%)\end{array}$ & $\begin{array}{l}\text { Non responder }(\mathrm{n}=7) \\
\text { N }(\%)\end{array}$ \\
\hline Median age, yr & 11.4 & 12.2 \\
\hline Median BMI, $\mathrm{kg} / \mathrm{m}^{2}$ & 17.7 & 16.8 \\
\hline Female sex & $14(60)$ & $4(57)$ \\
\hline Caucasian & $12(52)$ & $4(57)$ \\
\hline $\mathrm{FEV}_{1}<40 \%$ & $2 \quad(9)$ & 0 \\
\hline $\begin{array}{l}\text { Persistent infection } \\
\text { Haemophilus influenzae } \\
\text { Staphylococcus aureus } \\
\text { Streptococcus pneumoniae } \\
\text { Pseudomonas aeruginosa }\end{array}$ & $\begin{array}{ll}5 & (22) \\
1 & (4) \\
2 & (9) \\
0 & \end{array}$ & \begin{tabular}{|ll}
1 & $(14)$ \\
1 & $(14)$ \\
0 & \\
2 & $(9)$ \\
\end{tabular} \\
\hline Prophylactic antibiotic & $17(74)$ & $6(86)$ \\
\hline Mucolytic agent & $7 \quad(30)$ & $1(14)$ \\
\hline
\end{tabular}

the first clinically diagnosed pulmonary exacerbation treated with intravenous antibiotics. The best $\mathrm{FEV}_{1}$ in the 3 months after treatment and at 12 months was compared to the best $\mathrm{FEV}_{1}$ in the 12 months before treatment (baseline). Recovery to baseline was defined as any $\mathrm{FEV}_{1}$ after treatment that was greater than or equal to $90 \%$ of the baseline $\mathrm{FEV}_{1}$.

Results Of the 30 children treated for pulmonary exacerbations, $77 \%$ recovered to baseline lung function within 3 months and $73 \%$ at 12 months. There were no significant differences between the responders and non-responders in terms of age, sex, ethnicity, BMI, baseline $\mathrm{FEV}_{1}$, persistent sputum infection or use of antibiotic prophylaxis or mucolytic agent (Table).

Conclusions Similar to findings in CF, around 25\% PCD patients fail to recover to baseline lung function after treatment of a pulmonary exacerbation with intravenous antibiotics. Better treatment strategies are needed, and the results also suggest that prevention of exacerbations would be a useful end-point in clinical trials.

\section{P103 DO CHILDREN WITH PRIMARY CILIARY DYSKINESIA HARBOUR THE SAME PATHOGENS IN THE UPPER AND LOWER AIRWAY?}

GS Marsh, NL Collins, A Bush, C Hogg, SB Carr. Royal Brompton Hospital, London, UK

\subsection{6/thoraxjnl-2014-206260.244}

Background Primary ciliary dyskinesia (PCD) is characterised by chronic nasal discharge and lower respiratory tract infections. We aimed to assess the prevalence and concordance of pathogens present in samples from the upper (UA) and lower airway (LA) of children with PCD.

Method Microbiology samples from UA (naso-sinal lavage or nasal swab) and LA (sputum or cough swabs) were taken at the same time from children attending a specialist PCD centre, diagnosed on standard criteria (Eur Respir J 2009:34:1264-1276).

Results 70 children (30 male), median age 10.7 yrs (range 118 ), were studied. $36 / 70$ were prescribed long term prophylactic oral antibiotics. $42(60 \%)$ of UA samples were culture positive compared to $21(30 \%)$ positive LA samples. The UA positive group were not statistically different in age or $\mathrm{FEV}_{1} \%$ pred (11.1 vs 10 yrs and $78 \%$ vs $75 \%$ ). 14 patients were culture positive in both UA and LA, 10 of which had matched pathogens and 4 were unmatched. 20 were matched culture negative. The range of pathogens and where they were isolated are shown in the Table, some samples had more than one isolate.

Note the Table shows concordance for same pathogens Conclusion In PCD, pathogens are isolated far more commonly from the UA than the LA. The clinical impact of these pathogens in the long term is unknown. $11(16 \%)$ had PA in UA with only 2 of these having PA in their LA. We speculate that the UA may be, at least in some children, the source of LA infection. Clinical trials of eradication therapy after positive nasal cultures are indicated

\begin{tabular}{llll}
\multicolumn{2}{l}{ Abstract P103 Table 1} & & \\
\hline Micro-organism & UA+, LA+ & UA+, LA- & UA-, LA+ \\
\hline Strep pneumoniae & 4 & 14 & 1 \\
\hline H Influenzae & 4 & 11 & 8 \\
Staph. Aureus & 2 & 0 & 2 \\
Ps. Aeruginosa & 2 & 9 & 1 \\
Moraxella & 2 & 4 & 0 \\
Other & 0 & 3 & 0 \\
\hline
\end{tabular}




\section{P104 COMPARISON OF THE UPPER AND LOWER AIRWAY MICROBIOTA IN CHILDREN}

'B Ahmed, 'MJ Cox, ${ }^{1}$ WOC Cookson, ${ }^{1} J C$ Davies, ${ }^{1}$ MF Moffatt, ${ }^{2}$ A Bush. ${ }^{1}$ National Heart and Lung Institute, Imperial College London, London, UK; ${ }^{2}$ Department of Respiratory Paediatrics, Royal Brompton Hospital, London, UK

\subsection{6/thoraxjnl-2014-206260.245}

Introduction The lower airway microbiota is important in chronic lung disease but young children do not expectorate, making longitudinal studies difficult. Upper airway samples, of uncertain reliability, are used as a surrogate. Whilst throat swabs (TS) have shown differences in the microbiota between healthy and wheezing children [PLoS One 2012;7(10):e46803], the role of cough swabs (CS) is at present unclear. This study assessed the correlation between upper and lower airway samples as a prelude to a longitudinal study. We hypothesised that upper airway samples reflect the lower airway microbiota.

Methods TS and lower airway samples (bronchoalveolar lavage fluid, bronchial brushings or both) were collected from 55 children undergoing a clinically indicated fibre-optic bronchoscopy (FOB), including CS from 35 children. Bacterial DNA was extracted for quantitative PCR (qPCR) and 454 FLX pyrosequencing of the V3-V5 region of the 16S rRNA bacterial gene. Data analysis was performed with Quantitative Insights Into Microbial Ecology (QIIME) and Phyloseq in R.

Results FOB indications included: recurrent lower respiratory tract infections (47\%); cystic fibrosis (CF) (35\%), and Primary Ciliary Dyskinesia (PCD) (11\%). Only seven CS amplified successfully. 375,268 high quality 16S rRNA sequences were obtained from 132 upper and lower airway samples. No significant difference was seen in richness $(\mathrm{H}=1.352$, 2 d.f., $\mathrm{p}=0.509)$, evenness $(\mathrm{H}=3.942,2$ d.f, $\mathrm{p}=0.139)$, Shannon's diversity index $(\mathrm{H}=1.38,2$ d.f., $\mathrm{p}=0.501)$, and Inverse Simpson's diversity index $\left(\mathrm{F}_{(2,91)}=0.547, \mathrm{p}=0.581\right)$ between TS and lower airway samples. Beta-diversity (diversity between samples) was significantly different; $\leq 7.2 \%$ of variation in diversity attributed to the sampling method $(\mathrm{p}=0.002)$. Greater variation was observed between underlying pathologies and between patients $(\leq 41.2 \%$ and $68.3 \%$ respectively, $\mathrm{p}=0.001$ ).

Conclusions CS are not useful for pyrosequencing. TS are predictive of the lower airway microbiota and can differentiate diseases. TS are therefore potentially useful in studying longitudinal changes in the microbiota in children with chronic lung diseases.

\section{P105 SAFETY, FEASIBILITY AND QUALITY OF SPUTUM INDUCTION IN PRESCHOOL CHILDREN WITH OBSTRUCTIVE AIRWAYS DISEASE}

${ }^{1} \mathrm{~K}$ Robson, ${ }^{2} \mathrm{P}$ Nagakumar, ${ }^{1} \mathrm{~N}$ Collins, ${ }^{2} \mathrm{JC}$ Davies, ${ }^{2} \mathrm{~L}$ Fleming, ${ }^{1} \mathrm{I}$ Balfour-Lynn, ${ }^{1} \mathrm{M}$ Rosenthal, ${ }^{1} \mathrm{C}$ Hogg, ${ }^{1} \mathrm{~A}$ Jochmann, ${ }^{2} \mathrm{~A}$ Bush, ${ }^{2} \mathrm{~S}$ Saglani. 'Department of Paediatric Respiratory Medicine, Royal Brompton Hospital, London, UK; ${ }^{2}$ Department of Paediatric Respiratory Medicine, Royal Brompton Hospital; NHLI, Imperial College, London, UK

\subsection{6/thoraxjnl-2014-206260.246}

Introduction Airway infection and inflammation in infancy and preschool years contribute to the pathogenesis of cystic fibrosis (CF), severe wheezing and recurrent cough. However, the use of sputum induction (SI) to guide management in preschool children with obstructive airways disease remains under-explored. We hypothesised that SI can be performed safely in preschool
Abstract P105 Table 1

\begin{tabular}{|l|l|l|l|}
\hline Disease group & $\begin{array}{l}\text { Cystic fibrosis } \\
(n=14)\end{array}$ & $\begin{array}{l}\text { Preschool } \\
\text { wheeze } \\
(n=11)\end{array}$ & $\begin{array}{l}\text { Recurrent } \\
\text { cough }(n=10)\end{array}$ \\
\hline Age (months) & $40(16-60)$ & $33(15-54)$ & $29.5(7-70)$ \\
\hline Bacterial growth & $3 / 14(21 \%)$ & $1 / 11(9 \%)$ & $7 / 10(70 \%)$ \\
\hline Virus isolation & $2 / 14(14 \%)$ & $4 / 11(36 \%)$ & $3 / 10(30 \%)$ \\
\hline Cytology ( $n=29)$ & $5 / 10(50 \%)$ & $4 / 11(36.3 \%)$ & $4 / 8(50 \%)$ \\
\hline Neutrophils(\%) & $45(25-80)$ & $30(20-80)$ & $50(25-70)$ \\
\hline
\end{tabular}

children with obstructive airways disease, and that samples of sufficient quality to assess infection and inflammation can be obtained.

Methods SI was performed using nebulised hypertonic saline, $3.5 \%$ if there was a history of wheeze or $7 \%$ if the child had no wheeze or a diagnosis of CF. The procedure was undertaken for 15 min and safety was assessed using pulse-oximetry and auscultation. Physiotherapy, followed by a cough/oropharyngeal swab (CS), and oropharyngeal suction (OS) were undertaken to obtain samples. All samples were analysed for bacterial culture and viral PCR, a sub-set were processed for cytology.

Results 35 children (16 males), median age 32 months (range 7-70 months) were included. 32/35 (91\%) completed the procedure. The remaining three did not complete nebulisation as they became too upset, but underwent sample collection. None of the patients had any drop in oxygen saturation or increased respiratory symptoms. $16 / 35(46 \%)$ patients had positive pathogen identification (22 separate bacterial or viral isolates) from SI samples obtained by OS. Only 3/35 (9\%) positive isolates were identified from CS. 29/35 samples were able to be processed for cytology (see Table 1)

Conclusions Performance of SI was safe, feasible and well tolerated by preschool children with a range of obstructive airways diseases. Pathogen identification was significantly higher in samples obtained by OS compared to CS. Samples were of sufficient quality for cytological analysis in approximately half the patients. Future work will determine the clinical utility of SI as a noninvasive sample to guide therapy in preschool obstructive airways disease.

\section{P106 SPUTUM INDUCTION REDUCES THE NEED FOR BRONCHOSCOPY IN SCHOOL-AGED CHILDREN WITH CYSTIC FIBROSIS}

${ }^{1} \mathrm{~N}$ Collins, ${ }^{2} \mathrm{~K}$ Robson, ${ }^{2} \mathrm{P}$ Nagakumar, ${ }^{3} \mathrm{~S}$ Saglani, ${ }^{4} \mathrm{NWG}$ Voase, ${ }^{3} \mathrm{JC}$ Davies. ${ }^{1}$ Department of Physiotherapy, Royal Brompton Hospital, London, UK; ${ }^{2}$ Department of Paediatric Respiratory Medicine, Royal Brompton Hospital, London, UK; ${ }^{3}$ Department of Paediatric Respiratory Medicine, Royal Brompton Hospital and NHLI, Imperial College, London, UK; ${ }^{4}$ Respiratory Biomedical Research Unit, Royal Brompton Hospital, London, UK

\subsection{6/thoraxjnl-2014-206260.247}

Background Early detection of organisms such as Pseudomonas aeruginosa in CF is essential for successful eradication but is difficult in children, relying largely on non-invasive methods such as cough swabs $(\mathrm{C} / \mathrm{S})$ with sub-optimal sensitivity and specificity. Bronchoalvelolar lavage (BAL) remains the gold standard but disadvantages are its invasive nature, high cost and inability to be performed frequently. Sputum induction (SI) has previously been 